OPEN ACCESS

Edited by:

Clara Grilo,

Federal University of Lavras, Brazil

Reviewed by:

Davide M. Dominoni,

Netherlands Institute of Ecology (NIOO-KNAW), Netherlands

Andrea Olive,

University of Toronto, Canada

*Correspondence:

Molly K. Grace

molly.grace@ucf.edu

Specialty section:

This article was submitted to

Urban Ecology,

a section of the journal

Frontiers in Ecology and Evolution

Received: 29 November 2016 Accepted: 02 June 2017

Published: 20 June 2017

Citation:

Grace MK, Smith DJ and Noss RF (2017) Roadside Abundance of Anurans within a Community

Correlates with Reproductive Investment. Front. Ecol. Evol. 5:65. doi: 10.3389/fevo.2017.00065

\section{Roadside Abundance of Anurans within a Community Correlates with Reproductive Investment}

\author{
Molly K. Grace *, Daniel J. Smith and Reed F. Noss \\ Biology Department, University of Central Florida, Orlando, FL, United States
}

Roads and their associated effects (road-kill, pollution, etc.) have a largely negative impact on animals, especially amphibians, but not all species are affected to the same degree. Variation in life histories may explain some of these differences. Here, we examine how abundance of anuran species in roadside habitats is correlated with an aspect of reproductive life history: number of eggs produced by a female per year. Using data from a 1.5-year monitoring project in Central Florida, we found a positive correlation between the number of eggs produced by an average female of a species and the proportion of individuals found in roadside habitats compared to control habitats. This implies either that populations of species with a greater reproductive rate are able to rebound more quickly from negative road impacts, or that there is a strong selective pressure on species with low reproductive rates to avoid roads.

Keywords: amphibian, conservation biology, frog, road ecology, transportation

\section{INTRODUCTION}

The field of road ecology still seeks answers to fundamental questions, including which species are most at risk when roads are created and why. In most cases, roads have a negative effect on animal populations (reviewed in Fahrig and Rytwinski, 2009). However, some species are more negatively impacted than others. One of the most common effects of roads is reduced abundance. A recent meta-analysis found that the magnitude of this effect varies with life history traits; in particular, roadside abundance decreases as reproductive rate decreases (Rytwinski and Fahrig, 2012). In essence, species with low reproductive rates and late ages at maturity are more vulnerable than species which breed prolifically and mature quickly.

Anurans (frogs and toads) are currently experiencing severe declines worldwide, with local and species-level extinctions (Alford and Richards, 1999; Beebee and Griffiths, 2005; Halliday, 2005). Unfortunately, they also appear to be one of the taxa most negatively affected by roads (reviewed in Andrews et al., 2008; Fahrig and Rytwinski, 2009). In addition, the meta-analysis by Rytwinski and Fahrig (2012) found that anurans exhibit the aforementioned relationship between life history traits and abundance near roads, where species with a low reproductive rate are less abundant in roadside areas.

While meta-analyses are powerful, they present a general trend for the group being considered, often using species from distant areas of the world, and may not provide insight on a fine scale, i.e., the local or community level. Factors like interspecific competition and/or differences in habitat preference (Creusere and Whitford, 1976; Sazima and Eterovick, 2000) may have a greater influence than life history traits on the pattern of anuran abundance near roads within a community. However, if the relationship between life history and roadside abundance does hold on a smaller 
scale, roads could have a strong influence on community composition. Rytwinski and Fahrig (2011) investigated the relationship between mammal body size, mobility, and reproductive rate and traffic density within a landscape and found that reproductive rate is an explanatory factor in roadside community structure, echoing the global trend seen in the metaanalysis. Here, we investigate whether the community-level correlation between reproductive rate and roadside abundance also holds for anurans.

We assessed the relationship between reproductive rate and roadside abundance in anurans in Ocala National Forest (Florida, United States). Amphibians in general appear to be highly susceptible to traffic mortality and anurans have been identified as highly vulnerable to road effects (Fahrig and Rytwinski, 2009; Rytwinski and Fahrig, 2012; Smith, 2012; Beebee, 2013). We predicted that populations of species that produce larger numbers of offspring would be better able to compensate for these negative effects and would be found in higher abundances near roads.

\section{MATERIALS AND METHODS}

\section{Trap Surveys}

We examined data collected along two sections $(\approx 3.5 \mathrm{~km}$ each) of State Road 40 (Ocala, Florida, United States) from February 2012-July 2013 as part of a study for the Florida Department of Transportation (FDOT) to assess animal species richness and abundance (including anuran abundance) to collect baseline data prior to expansion of the highway (Figure 1). Monitoring the area for at least a year allowed us to observe most anuran species in the area, whose activity levels vary throughout the year by species (e.g., winter breeders vs. summer breeders). Because the goal of data collection was to thoroughly sample the different habitat types along the highway, our extensive monitoring of this area generated a large biological dataset. The stretch of SR 40 that we studied is located in Ocala National Forest and Silver River State Park, in Marion County, and has an annual average traffic volume of about 11,000 vehicles/day. All other roads within $5 \mathrm{~km}$ of the study sites were either unpaved trails or had traffic volumes $<2,000$ vehicles/day (Figure 1). Such low traffic volumes have been shown to have little to no effect on anuran abundance (Eigenbrod et al., 2008a). The primary vegetation types in the area are wet pine flatwoods, hardwood swamp, and upland mixed hardwood-pine forest.

Within the two study sections, we subsampled the area with roadside and control traps to monitor anuran abundance in the area. Each roadside trap consisted of a 30-m long drift fence positioned parallel to the road in the right-of-way $(\sim 10-$ $20 \mathrm{~m}$ from the road surface). Four bucket traps and four screen funnel traps were positioned along each drift fence. Control traps followed the same design, but were placed $\sim 500 \mathrm{~m}$ from the road. Due to heterogeneity of environmental conditions (vegetation, water table, etc.) it was impossible to space control traps at completely uniform distances from the road (mean $558 \mathrm{~m}$; range $315-870 \mathrm{~m}$ ). To ensure that our subsampling effort was uniform between roadside and control areas, we were careful to place roadside and control traps equally within the different vegetation types found in the area (wet pine flatwoods, hardwood swamp, and upland mixed hardwood-pine forest). These three habitat types are important to the anuran species in the area during different times of the year (ephemeral pools in flatwoods for egg deposition, permanent water in swamps for aquatic species, and upland forest during the non-breeding season for terrestrial species) so sampling in all three increased our coverage of the area and the likelihood that we would trap the majority of anuran species.

Traps were checked in the morning for 3-4 consecutive days each week. During periods when traps were not being checked regularly, they were shut to prevent animals from entering. All animals found in the trap arrays were identified to species and age class and marked in order to note recaptures.

This research was approved by the Institutional Animal Care and Use Committee at the University of Central Florida under protocol \#11-37W and conducted under Scientific Collecting Permit \#LSSC-11-00092.

\section{Measurement of Reproductive Investment}

We used the average number of eggs/yr produced by a female (eggs/clutch*number of clutches per year) as a measure of the reproductive investment of each anuran species. To avoid autocorrelation, we chose not to use age to reproductive maturity of females as an independent variable because age at maturity correlates with body size, which greatly influences the number of eggs produced (Gibbons and McCarthy, 1986; Berven, 1988).

To determine the average number of eggs laid by females of each species in a year, we referenced two guides to Florida amphibians (Ashton and Ashton, 1988; Bartlett and Bartlett, 2011). If the number of eggs was reported as a range (for example, 200-300 eggs), we took the average of the two values (e.g., 250 eggs). If it was reported as being "up to" a certain number, we halved that number, as it is likely that these reports were of extreme observations. If it was reported as "more than" a number, we reported that number. Obviously, this method of determining reproductive rate is by no means exact, but we believe that it is successful in approximating the true pattern (i.e., "this species generally produces more eggs, while this species generally produces fewer"). We then used the average from the two guides as the final number. If only one book gave information for a particular species, we used the value it reported. If no information for that particular species or subspecies was found, we used a guide to United States amphibians (not Floridaspecific) to obtain the value for the species (Lannoo et al., 2005). See Supplementary Table 1 for full details on how each species' value for averages eggs/year was determined.

\section{GLM Analysis}

We analyzed the relationship between reproductive investment and species presence near roads using a generalized linear model in the program R v3.0.1 ( $\mathrm{R}$ Development Core Team, 2013). The spatial unit of interest was section (east vs. west) and data from roadside and control trap subsamples were pooled for each section. In order to compare species with different numbers of individuals found, we converted data to proportions. Within each area, we summed the total number of individuals of a species 


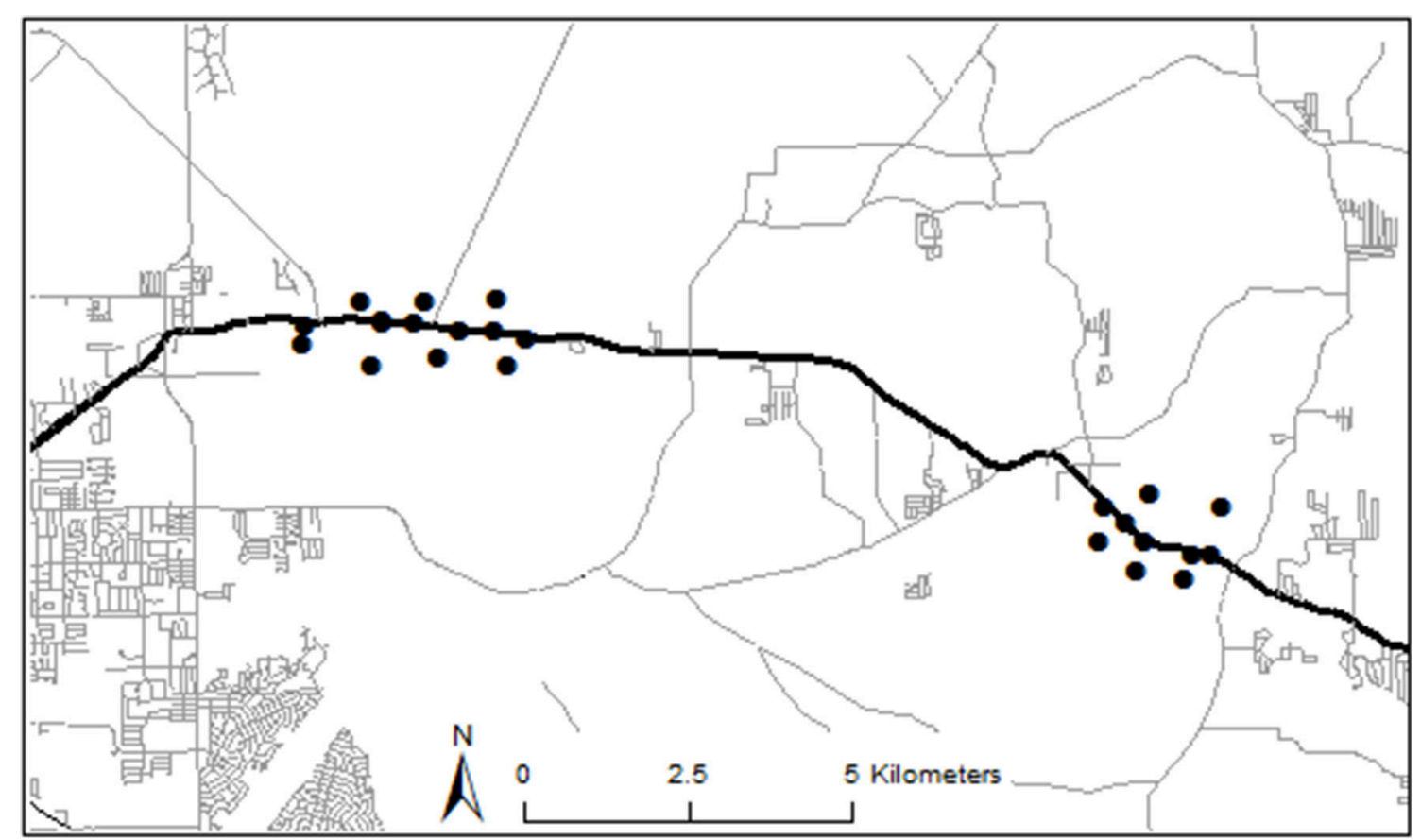

FIGURE 1 | Map of trap locations and nearby roads. State Road 40 is denoted by the thick black east-west line. Trap locations are denoted by black dots. Two dots indicating roadside traps in the western section appear to overlap on map, but they were separated by $\approx 100 \mathrm{~m}$ and were on different sides of the road. All paved roads within $5 \mathrm{~km}$ of study locations have annual average daily traffic volume (AADT) $<2,000$ cars/day. Unpaved roads and trails were omitted from this map for clarity.

found in roadside traps and control traps and calculated the proportion of individuals of that species found at roadside traps. Because our dependent variable was proportional, we tested for the effects of eggs/female/year (ln-transformed due to the wide range of values) and section using a binomial generalized linear model $[$ glm(roadside proportion $\sim \ln ($ eggs $/ y r)+$ section, family $=$ binomial)].

\section{Model Weighting}

We observed low numbers of certain species in our traps (Table 1), particularly treefrogs (Hyla spp.). Drift fences and bucket traps are not efficient methods for trapping treefrogs, since they can easily escape them (Dodd, 1991). Although this caveat applies to both roadside and control traps equally, low sample size could result in a calculated roadside proportion that does not reflect the true pattern of roadside vs. control abundance, simply by chance. However, the larger the total number of individuals observed, the more confident we can be that the roadside proportion of individuals is biologically significant. Therefore, in our model we weighted the data point for each species' calculated roadside proportion using the "weights" argument in the R function used to fit the generalized linear model, $\operatorname{glm}()$. Including "weights" in the model ensures that data points with higher weights contribute more to final parameter estimates. We established a cutoff number of total observations below which the calculated proportion for a species became unreliable, and weighted those data points to have less influence than the rest of the data points.
We determined the cutoff using the following equation modified from Krebs (1999):

$$
\mathrm{n}=\frac{4 \hat{\mathrm{p}}(1-\widehat{\mathrm{p}})}{\mathrm{d}^{2}}
$$

where $\mathrm{n}=$ the required sample size, $\hat{\mathrm{p}}=$ the observed proportion, and $\mathrm{d}=$ the desired margin of error. The most conservative sample size estimate is given when assuming that $\hat{\mathrm{p}}=0.5$ (Krebs, 1999), which is what we used. Using this formula, in order to achieve a margin of error no greater than $\pm 10 \%(\mathrm{~d}=0.1)$, the minimum sample size is 100 individuals. If a species total fell below the minimum sample size, it was weighted by dividing the number of individuals observed by 100 . All species with 100 or more observed individuals received a weight of 1 .

\section{RESULTS}

We observed 17 anuran species, with greatly varying reproductive rates (20-9,000 eggs/yr), in both roadside and control trap arrays (Table 1). Fourteen species were observed in both the west and east sections, though two species were observed only in the west section (Florida gopher frog, Rana capito aesopus and Florida chorus frog, Pseudacris nigrita verrucosa) and one species was only observed in the east section (little grass frog, Pseudacris ocularis; Table 1). Though the species we observed represent multiple families and different life histories (e.g., classic egg deposition in water vs. deposition on land, as in Eleutherodactylus planirostris), we observed a positive 
TABLE 1 | List of anuran species encountered in trap surveys.

\begin{tabular}{|c|c|c|c|c|c|c|c|}
\hline Species binomial & Common name & Family* & Eggs/yr & Sec. & Road prop. & Obs. & Weight \\
\hline \multirow[t]{2}{*}{ Acris gryllus dorsalis } & Southern cricket frog & $\mathrm{H}$ & 125 & W & 0.60 & 10 & 0.10 \\
\hline & & & & $E$ & 0.23 & 197 & 1.00 \\
\hline \multirow[t]{2}{*}{ Anaxyrus quercicus } & Oak toad & B & 210 & W & 0.19 & 16 & 0.16 \\
\hline & & & & $E$ & 0.11 & 136 & 1.00 \\
\hline \multirow[t]{2}{*}{ Anaxyrus terrestris } & Southern toad & $\mathrm{B}$ & 3,500 & W & 0.32 & 332 & 1.00 \\
\hline & & & & $E$ & 0.18 & 56 & 0.56 \\
\hline \multirow[t]{2}{*}{ Eleutherodactylus p. planirostris } & Greenhouse frog & $E$ & 20 & W & 0.12 & 370 & 1.00 \\
\hline & & & & $E$ & 0.18 & 40 & 0.40 \\
\hline \multirow[t]{2}{*}{ Gastrophryne carolinensis } & Eastern narrow-mouthed toad & M & 800 & W & 0.33 & 650 & 1.00 \\
\hline & & & & $E$ & 0.46 & 214 & 1.00 \\
\hline \multirow[t]{2}{*}{ Hyla cinerea } & Green treefrog & $\mathrm{H}$ & 645 & W & 0.38 & 8 & 0.08 \\
\hline & & & & $E$ & 0.00 & 2 & 0.02 \\
\hline \multirow[t]{2}{*}{ Hyla femoralis } & Pinewoods treefrog & $\mathrm{H}$ & 275 & W & 0.25 & 12 & 0.12 \\
\hline & & & & $E$ & 0.035 & 57 & 0.57 \\
\hline \multirow[t]{2}{*}{ Hyla gratiosa } & Barking treefrog & $\mathrm{H}$ & 1,125 & W & 0.67 & 6 & 0.06 \\
\hline & & & & $E$ & 0.20 & 5 & 0.05 \\
\hline \multirow[t]{2}{*}{ Hyla squirella } & Squirrel treefrog & $\mathrm{H}$ & 650 & W & 0.14 & 28 & 0.28 \\
\hline & & & & $E$ & 0.50 & 4 & 0.04 \\
\hline \multirow[t]{2}{*}{ Pseudacris crucifer bartramiana } & Southern spring peeper & $\mathrm{H}$ & 100 & W & 0.25 & 8 & 0.08 \\
\hline & & & & $E$ & 0.33 & 3 & 0.03 \\
\hline Pseudacris nigrita verrucosa & Florida chorus frog & $\mathrm{H}$ & 117.5 & W & 0.71 & 7 & 0.07 \\
\hline Pseudacris ocularis & Little grass frog & $\mathrm{H}$ & 100 & $E$ & 0.00 & 10 & 0.10 \\
\hline \multirow[t]{2}{*}{ Rana c. clamitans } & Bronze frog & $\mathrm{R}$ & 2,000 & W & 0.00 & 1 & 0.01 \\
\hline & & & & $E$ & 0.00 & 1 & 0.01 \\
\hline Rana capito aesopus & Florida gopher frog & $\mathrm{R}$ & 1,750 & W & 0.00 & 1 & 0.01 \\
\hline \multirow[t]{2}{*}{ Rana grylio } & Pig frog & $\mathrm{R}$ & 9,000 & W & 1.000 & 1 & 0.010 \\
\hline & & & & $E$ & 1.000 & 4 & 0.040 \\
\hline \multirow[t]{2}{*}{ Rana sphenocephala } & Southern leopard frog & $\mathrm{R}$ & 1,000 & W & 0.694 & 111 & 1.000 \\
\hline & & & & $E$ & 0.583 & 24 & 0.240 \\
\hline \multirow[t]{2}{*}{ Scaphiopus holbrookii } & Eastern spadefoot toad & S & 150 & W & 0.081 & 604 & 1.000 \\
\hline & & & & $E$ & 0.154 & 52 & 0.520 \\
\hline
\end{tabular}

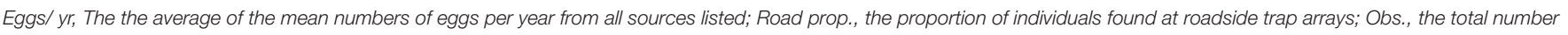

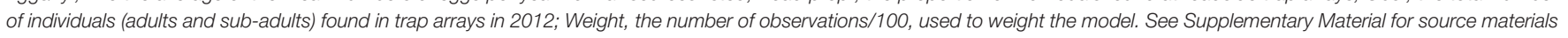
used to determine reproductive rate for each species.

*Family names: B, Bufonidae; E, Eleutherodactylidae; H, Hylidae; M, Microhylidae; R, Ranidae; S, Scaphiopodidae.

correlation between number of eggs produced and roadside abundance (Figure 2, Table 2). In some cases, species with high reproductive rates had low abundance near roads and vice versa, but it appears that this may be a stochastic effect of low sample size and may not truly reflect the pattern within the species (this is reflected in low weighting of points with low sample size; Figure 2). There was a statistically significant effect of section (Table 2), however, the direction of the trend remains consistent between the two section (Figure 2).

\section{DISCUSSION}

Our results support the hypothesis that certain life history traits make species more vulnerable to the negative effects of roads (Rytwinski and Fahrig, 2012). In particular, we found that as anuran reproductive rate increases, anuran roadside abundance also increases, a pattern that has previously been noted in mammals (Rytwinski and Fahrig, 2011). Although our measure of the effects of roads on anuran demography is indirect, it provides a basis for predictions about the vulnerability of particular species to road mortality or population fragmentation. Given that our model did not explain all of the variance, there are undoubtedly factors at play that our study could not account for, including preferred habitat and behavioral patterns. For example, in our study Southern Leopard Frogs Lithobates spenocephalus (=Rana spenocephala) displayed a roadside proportion of 0.674 , meaning that over half of the individuals caught were caught in roadside traps. This is probably explained by the fact that they often use roadside ditches to breed (Bridges and Semlitsch, 2001). However, knowing that some relationship between demography and roads exists is a critical piece of information for conservation biologists because it identifies certain species as particularly vulnerable to road effects, and therefore a higher priority for mitigation efforts. 


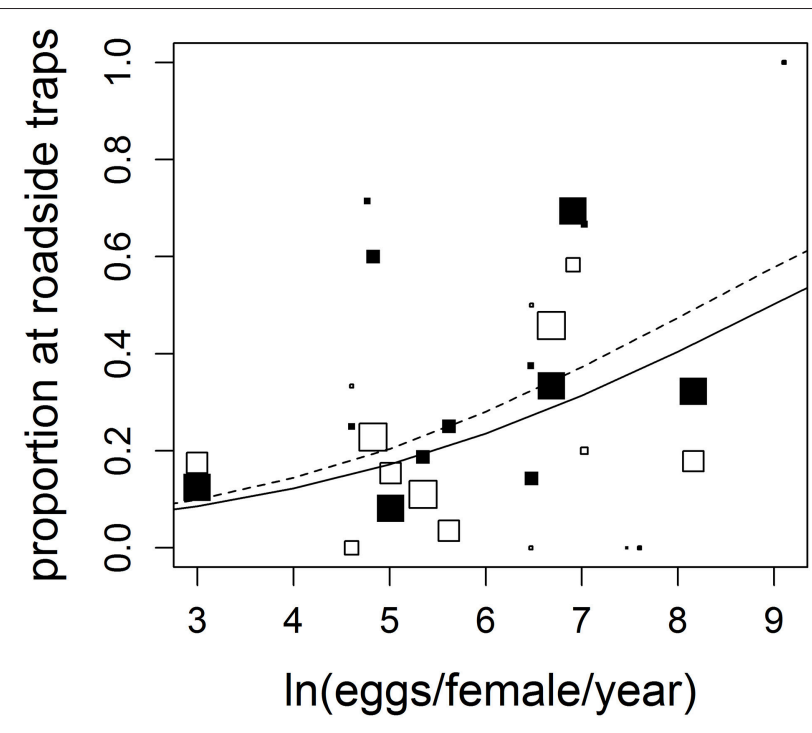

FIGURE 2 | Anuran species with higher reproductive rates were significantly more likely to be found in roadside traps. The black points represent species from the western section (solid line shows predicted model values) while the white points are from the eastern section (dashed line). Each point within each model represents one species. Species represented by smaller data points received lower weight in calculating model parameters because of lower sample size (see Section Materials and Methods). For full species names and sources for eggs/female/yr values, see Supplementary Material.

TABLE 2 | Anuran species that lay more eggs were found near SR 40 in higher proportions.

\begin{tabular}{lcccc}
\hline & Estimate & SE & z-value & $\operatorname{Pr}(>|\mathbf{z}|)$ \\
\hline Intercept & -3.57 & 0.218 & -16.4 & $<2 e^{-16}$ \\
In (eggs/female/year) & 0.399 & 0.0334 & 12.0 & $<2 e^{-16}$ \\
Section (east) & 0.236 & 0.105 & 2.24 & 0.0250 \\
\hline
\end{tabular}

Summary table for the weighted glm (roadside proportion $/ \mathrm{n}$ (eggs/yr) + section, family = binomial) where "roadside proportion" is the proportion of adult frogs of a species found at roadside traps against the average number of eggs laid by a female of that species per year. Null deviance: 359.66 on 30 degrees of freedom. Residual deviance: 195.87 on 28 degrees of freedom.

However, a crucial piece of information is still needed to make the leap from identification of the correlation to effective mitigation. Though species with particular life history traits are known to show increased reduction of abundance near roads, the mechanism behind this reduced abundance remains unknown. There are two primary hypotheses that propose a mechanism: reduced abundance of species with low reproductive rates near roads might be caused either by (1) differential impacts of direct mortality (road-kill) or (2) selection for behavioral road avoidance (Fahrig et al., 1995; Eigenbrod et al., 2009; Rytwinski and Fahrig, 2012).

Populations of species with a low reproductive rate should experience a greater negative effect of road mortality than species with a high reproductive rate because the fewer offspring individuals have, the longer it will take for a population to recover from mortality events (Gibbs and Shriver, 2002; Rytwinski and Fahrig, 2011). It is also possible that species with a lower reproductive rate are inherently more "risk-averse." We might expect that such species would be more likely to behaviorally avoid roads than species that experience less selective pressure for road avoidance, explaining their reduced abundance near roads. Knowing whether animal populations are actively avoiding roads or are simply dying on them is critical to implementing an effective mitigation strategy. If a species avoids roads, then making a road more permeable with wildlife overpasses or underpasses will not necessarily eliminate the barrier effect of that road, because traffic noise or other cues may trigger the avoidance behavior.

Unfortunately, determining whether a population is succumbing to mortality or behaviorally avoiding roads is not easy. Previous studies of road avoidance behavior have been logistically difficult, requiring extensive field observation or satellite/radio-tracking. Therefore, much data on the distribution of animals relative to roads has been collected, but data on behavioral responses to roads is generally lacking (Rytwinski and Fahrig, 2012). While it is easy to collect roadkill data, this cannot always be extrapolated to make inferences about avoidance behavior unless more information about the size and distribution about the population overall is known.

The available literature provides some reason to expect that anurans could display road avoidance behavior. Amphibians in general appear to be highly susceptible to traffic mortality (Fahrig and Rytwinski, 2009; Rytwinski and Fahrig, 2012; Beebee, 2013), and anurans have been identified as highly vulnerable to road effects (Fahrig and Rytwinski, 2009; Rytwinski and Fahrig, 2012; Smith, 2012; Beebee, 2013), which could select for road avoidance behavior. There is growing consensus that risktaking behavior and other aspects of animal "personality" have a genetic component (Stamps and Groothuis, 2010), which could allow selection for road avoidance. There may also be selective pressures for road avoidance besides road-kill: road noise has been shown to increase corticosterone levels in female Wood Frogs (Lithobates sylvaticus) and impair their ability to navigate to male breeding choruses (Tennessen et al., 2014). In addition, clear zones adjacent to roads are sometimes used by predators as efficient movement corridors or hunting areas (James and Stuart Smith, 2000; Colón, 2002; Laurance et al., 2004; Latham et al., 2011).

The available literature does not reject the possibility of road avoidance. Eigenbrod et al. (2008b) found that amphibian species richness was predicted better by the amount of habitat available without crossing a road (i.e., accessible habitat) than by total habitat. This indicates that some amphibian species may behaviorally avoid roads (Bouchard et al., 2009). Road mortality patterns also hint at species-specific, life-history-associated road avoidance: one study found that anuran roadkill was higher for a prolific breeder (Common Toads, Bufo bufo; $\sim 1,500$ eggs/yr, Beebee and Griffiths, 2000) than for a species with smaller clutch size (Fire-Bellied Toads, Bombina bombina; 80-300 eggs/yr, Lannoo et al., 2005) after controlling for how many animals attempted to cross the road using pitfall traps (Brzeziński et al., 2012). Fire-bellied toads approached the road less often than common toads and were hit less often when they did cross, indicating potential selection for avoidance of roads and also 
potentially vehicles. The one empirical study of anuran behavior near roads (Bouchard et al., 2009) observed no avoidance-all Northern Leopard Frogs (Rana pipiens), released near a road attempted to cross it-but this may not be a universal response across anuran species. Since, Northern Leopard Frogs have a high reproductive rate (645-7,648 eggs/clutch; Lannoo et al., 2005), the population may be less susceptible to road effects, making individuals less likely to avoid roads.

Amphibian-specific road crossings (ecopassages) are becoming more commonplace and may help to mitigate the negative effects of roads on anurans (Dodd et al., 2004). However, if roads elicit behavioral avoidance in some species, ecopassages will not be enough to mitigate their impact. In such cases it may be necessary to create new breeding ponds that can be reached without crossing roads (Beebee, 2013), or even to seasonally close roads to traffic (Jackson et al., 2015). Considering the rapid extinction of many amphibian species worldwide (e.g., Houlahan et al., 2000; Stuart et al., 2004), identifying threats to vulnerable species and the best way to mitigate those threats will be critical for maintaining amphibian biodiversity into the future.

\section{ETHICS STATEMENT}

This study was carried out in accordance with the recommendations of the University of Central Florida Institutional Animal Care and Use Committee under protocol \#11-37W and conducted under Scientific Collecting Permit \#LSSC-11-00092.

\section{REFERENCES}

Alford, R. A., and Richards, S. J. (1999). Global amphibian declines: a problem in applied ecology. Annu. Rev. Ecol. Syst. 30, 133-165. doi: 10.1146/annurev.ecolsys.30.1.133

Andrews, K. M., Gibbons, J. W., and Jochimsen, D. M. (2008). "Ecological effects of roads on amphibians and reptiles: a literature review," in Urban Herpetology, eds J. C. Mitchell, R. E. Jung Brown, and B. E. Bartholomew (Salt Lake: Society for the Study of Amphibians and Reptiles), 121-143.

Ashton, R. E., and Ashton, P. S. (1988). Handbook of Reptiles and Amphibians of Florida. Part Three: The Amphibians. Miami, FL: Windward Publishing.

Bartlett, R. D., and Bartlett, P. P. (2011). Florida's Frogs, Toads, and Other Amphibians: A Guide to Their Identification and Habits. Gainesville, FL: University Press of Florida.

Beebee, T. J. (2013). Effects of road mortality and mitigation measures on amphibian populations. Conserv. Biol. 27, 657-668. doi: 10.1111/cobi.12063

Beebee, T. J., and Griffiths, R. (2000). The New Naturalist: Amphibians and Reptiles-a Natural History of the British Herpetofauna. London: Harper Collins Publishers.

Beebee, T. J., and Griffiths, R. (2005). The amphibian decline crisis: a watershed for conservation biology? Biol. Conserv. 125, 271-285. doi: 10.1016/j.biocon.2005.04.009

Berven, K. A. (1988). Factors affecting variation in reproductive traits within a population of wood frogs (Rana sylvatica). Copeia 1988, 605-615. doi: $10.2307 / 1445378$

Bouchard, J., Ford, A. T., Eigenbrod, F. E., and Fahrig, L. (2009). Behavioral responses of northern leopard frogs (Rana pipiens) to roads and traffic: implications for population persistence. Ecol. Soc. 14:23. doi: 10.5751/ES-03022-140223

Bridges, C. M., and Semlitsch, R. D. (2001). Genetic variation in insecticide tolerance in a population of southern leopard frogs (Rana sphenocephala):

\section{AUTHOR CONTRIBUTIONS}

MG analyzed the data and wrote the bulk of the manuscript. DS and RN were principal investigators on the project that generated the data and co-wrote and edited the manuscript. All authors have given approval of the final version of this manuscript.

\section{FUNDING}

This project was funded completely by the Florida Department of Transportation under contract BDK78, TWO \#501-3.

\section{ACKNOWLEDGMENTS}

Thanks are extended to S. Tonjes, Florida DOT, for his oversight and support of this research. The work of M. Noss and $\mathrm{H}$. Chasez inputting and managing data was invaluable. We especially acknowledge the efforts of A. Casavant, D. Parker, F. Hayes, and the many other temporary biological technicians and volunteers that performed the field work on this project.

\section{SUPPLEMENTARY MATERIAL}

The Supplementary Material for this article can be found online at: http://journal.frontiersin.org/article/10.3389/fevo. 2017.00065/full\#supplementary-material

implications for amphibian conservation. Copeia 2001, 7-13. doi: 10.1643/ 0045-8511(2001)001[0007:GVIITI]2.0.CO;2

Brzeziński, M., Eliava, G., and Żmihorski, M. (2012). Road mortality of pondbreeding amphibians during spring migrations in the Mazurian Lakeland, NE Poland. Eur. J. Wildlife Res. 58, 685-693. doi: 10.1007/s10344-0120618-2

Colón, C. P. (2002). Ranging behaviour and activity of the Malay civet (Viverra tangalunga) in a logged and an unlogged forest in Danum valley, East Malaysia. J. Zool. 257, 473-485. doi: 10.1017/S0952836902001073

Creusere, F. M., and Whitford, W. G. (1976). Ecological relationships in a desert anuran community. Herpetologica 32, 7-18.

Dodd, C. K. (1991). Drift fence-associated sampling bias of amphibians at a Florida sandhills temporary pond. J. Herpetol. 25, 296-301. doi: 10.2307/1564587

Dodd, C. K., Barichivich, W. J., and Smith, L. L. (2004). Effectiveness of a barrier wall and culverts in reducing wildlife mortality on a heavily traveled highway in Florida. Biol. Conserv. 118, 619-631. doi: 10.1016/j.biocon.2003. 10.011

Eigenbrod, F., Hecnar, S. J., and Fahrig, L. (2008a). The relative effects of road traffic and forest cover on anuran populations. Biol. Conserv. 141, 35-46. doi: 10.1016/j.biocon.2007.08.025

Eigenbrod, F., Hecnar, S. J., and Fahrig, L. (2008b). Accessible habitat: an improved measure of the effects of habitat loss and roads on wildlife populations. Landscape Ecol. 23, 159-168. doi: 10.1007/s10980-007-9174-7

Eigenbrod, F., Hecnar, S. J., and Fahrig, L. (2009). Quantifying the road effect zone: threshold effects of a motorway on anuran populations in Ontario, Canada. Ecol. Soc. 14:24. doi: 10.5751/ES-02691-140124

Fahrig, L., Pedlar, J. H., Pope, S. E., Taylor, P. D., and Wegner, J. F. (1995). Effect of road traffic on amphibian density. Biol. Conserv. 73, 177-182. doi: 10.1016/0006-3207(94)00102-V

Fahrig, L., and Rytwinski, T. (2009). Effects of roads on animal abundance: an empirical review and synthesis. Ecol. Soc. 14:21. doi: 10.5751/ES-02815-140121 
Gibbons, M. M., and McCarthy, T. K. (1986). The reproductive output of frogs Rana temporaria (L) with particular reference to body size and age. J. Zool. 209, 579-593. doi: 10.1111/j.1469-7998.1986.tb03613.x

Gibbs, J. P., and Shriver, W. G. (2002). Estimating the effects of road mortality on turtle populations. Conserv. Biol. 16, 1647-1652. doi: 10.1046/j.1523-1739.2002.01215.x

Halliday, T. (2005). "Diverse phenomena influencing amphibian population declines," in Amphibian Declines: The Conservation Status of United States Species, ed M. J. Lannoo (Berkeley, CA: University of California Press), 3-6.

Houlahan, J. E., Findlay, C. S., Schmidt, B. R., Meyer, A. H., and Kuzmin, S. L. (2000). Quantitative evidence for global amphibian population declines. Nature 404, 752-755. doi: 10.1038/35008052

Jackson, S. D., Smith, D. J., and Gunson, K. E. (2015). "Mitigating road effects on small animals," in Roads and Ecological Infrastructure, eds K. M. Andrews, P. Nanjappa, and S. P. D. Riley (Baltimore, MD: Johns Hopkins University Press), $177-207$.

James, A. R., and Stuart-Smith, A. K. (2000). Distribution of caribou and wolves in relation to linear corridors. J. Wildlife Manage. 2000, 154-159. doi: $10.2307 / 3802985$

Krebs, C. J. (1999). Ecological Methodology. San Francisco, CA: Benjamin/Cummings.

Lannoo, M. J., Gallant, A. L., Nanjappa, P., Blackburn, L., and Hendricks, R. (2005). "Anura," in Amphibian Declines: The Conservation Status of United States Species, ed M. J. Lannoo (Berkeley, CA: University of California Press), 381-600.

Latham, A. D. M., Latham, M. C., Boyce, M. S., and Boutin, S. (2011). Movement responses by wolves to industrial linear features and their effect on woodland caribou in northeastern Alberta. Ecol. Appl. 21, 2854-2865. doi: $10.1890 / 11-0666.1$

Laurance, S. G., Stouffer, P. C., and Laurance, W. F. (2004). Effects of road clearings on movement patterns of understory rainforest birds in central Amazonia. Conserv. Biol. 18, 1099-1109. doi: 10.1111/j.1523-1739.2004.00268.x

R Development Core Team (2013). R: A Language and Environment for Statistical Computing. Vienna: R Foundation for Statistical Computing. Available online at: http://www.R-project.org/
Rytwinski, T., and Fahrig, L. (2011). Reproductive rate and body size predict road impacts on mammal abundance. Ecol. Appl. 21, 589-600. doi: 10.1890/10-0968.1

Rytwinski, T., and Fahrig, L. (2012). Do species life history traits explain population responses to roads? A meta-analysis. Biol. Conserv. 147, 87-98. doi: 10.1016/j.biocon.2011.11.023

Sazima, I., and Eterovick, P. C. (2000). Structure of an anuran community in a montane meadow in southeastern Brazil: effects of seasonality, habitat, and predation. Amphib. Reptil. 21, 439-461. doi: 10.1163/156853800300 059331

Smith, D. J. (2012). Determining location and design of cost effective wildlife crossing structures along US 64 in North Carolina. Transp. Res. Record 2270, 31-38. doi: 10.3141/2270-05

Stamps, J., and Groothuis, T. G. (2010). The development of animal personality: relevance, concepts and perspectives. Biol. Rev. 85, 301-325. doi: 10.1111/j.1469-185X.2009. 00103.x

Stuart, S. N., Chanson, J. S., Cox, N. A., Young, B. E., Rodrigues, A. S., Fischman, D. L., et al. (2004). Status and trends of amphibian declines and extinctions worldwide. Science 306, 1783-1786. doi: 10.1126/science.11 03538

Tennessen, J. B., Parks, S. E., and Langkilde, T. (2014). Traffic noise causes physiological stress and impairs breeding migration behaviour in frogs. Conserv. Physiol. 2:cou032. doi: 10.1093/conphys/cou032

Conflict of Interest Statement: The authors declare that the research was conducted in the absence of any commercial or financial relationships that could be construed as a potential conflict of interest.

Copyright $\odot 2017$ Grace, Smith and Noss. This is an open-access article distributed under the terms of the Creative Commons Attribution License (CC BY). The use, distribution or reproduction in other forums is permitted, provided the original author(s) or licensor are credited and that the original publication in this journal is cited, in accordance with accepted academic practice. No use, distribution or reproduction is permitted which does not comply with these terms. 